\title{
Performance and dominant strategies on place and cue tasks following hippocampal lesions in rats
}

\author{
HIROSHIGE OKAICHI \\ Doshisha University, Kyoto, Japan
}

\begin{abstract}
Rats with hippocampal lesions, sham operated rats, and unoperated controls were trained on a place task and a cue task in an elevated T-maze. The extent to which various strategies (place, cue, response) were employed by the rats in learning the tasks were of special interest. The hippocampals were significantly impaired on the place task but not on the cue task. These animals used an appropriate cue strategy on the cue task, but an inappropriate response strategy (left or right turn) on the place task. In contrast, control rats performed well and used appropriate strategies on both tasks. The results of the present experiment show that rats with hippocampal lesions are especially impaired in learning a place task; these results support the cognitive map theory of O'Keefe and Nadel (1978).
\end{abstract}

According to the cognitive map theory of O'Keefe and Nadel (1978), damage to the hippocampus should serve to impair the ability of rats to learn to approach a specific place in the environment. However, learning a discrimination based on intramaze cues and learning to make a specific response (go right or go left) should not be affected. According to the theory, learning based on cues or position should show facilitation following hippocampectomy, because there would not be any interference from a place-learning strategy (O'Keefe \& Nadel, 1978, p. 269). Experiments to date have not produced decisive results; some support the cognitive map theory (Jarrard, Okaichi, Steward, \& Goldschmidt, 1984; Morris, Garrud, Rawlins, \& O'Keefe, 1982; Nadel \& MacDonald, 1980), but others do not (Olton \& Feustle, 1981; Walker \& Olton, 1984; Winocur, 1980, 1982).

The present experiment was designed to clarify this issue by directly comparing place and cue learning in a Tmaze. Specifically, the place task was characterized by numerous extramaze cues and the subjects were required to go to a specific place, whereas in the cue task there were obvious intramaze cues that identified the correct arm. In previous experiments using the radial arm maze (Nadel \& MacDonald, 1980) and the cross maze (Olton \& Feustle, 1981), rats were required in the place and cue tasks to remember during the trial which arms had already been chosen and to choose arms that had not yet been chosen. In contrast, the T-maze used in the present experiment simply requires the rats to learn to discriminate between two arms and make the appropriate response. In terms of the reference memory-working memory distinc-

The author thanks Leonard E. Jarrard for his helpful comments on the manuscript. Any errors are the responsibility of the author. Requests for reprints should be sent to Hiroshige Okaichi, Department of Psychology, Doshisha University, Kyoto 602, Japan. tion advanced by Olton, Becker, and Handelmann (1979), correct performance on this $\mathrm{T}$-maze task should involve reference and not working memory. Learning the place and cue tasks in the T-maze should not be as difficult for rats as procedures used in other experiments designed to test place versus cue learning in hippocampectomized rats; therefore, the present research should provide a more direct test of the cognitive map theory. The present experiment was designed so that the kind of strategy (place, cue, response) used by the rats in learning the tasks could be specified.

\section{METHOD}

\section{Subjects}

Forty male albino rats of the Wistar strain served as subjects. They were housed individually during training. Twenty-three of the animals were assigned to the hippocampal group, 10 served as operated controls, and 7 were unoperated controls and thus received no operation.

\section{Surgical and Histological Procedures}

All operated rats were treated with $0.05 \mathrm{cc}$ of atropine sulfate IM, and then anesthetized with sodium pentobarbital $(50 \mathrm{mg} / \mathrm{kg}$ ) IP. The hippocampal lesions were produced by radio frequency (Radionics, FRG-4), which passed current through an electrode insulated except for $1 \mathrm{~mm}$ at the tip. The skull was level and the four coordinates at which the tip of the electrode was inserted were $\mathrm{AP}=-2.1, \mathrm{ML}= \pm 1.8$ and $\pm 2.7, \mathrm{DV}=-3.8 \mathrm{~mm}$ from bregma. The temperature at the tip was maintained at $56^{\circ} \mathrm{C}$ for $60 \mathrm{sec}$. The tip of the electrode for the operated controls was also inserted at four coordinates $(\mathrm{AP}=-2.1, \mathrm{ML}= \pm 1.8$ and \pm 2.7 , DV $=-2.8$ ), but no current was passed.

After behavioral testing, all operated rats were anesthetized with an oxerdose of sodium pentobarbital and perfused intracardially with $10 \%$ formalin. The brains were removed, soaked in formalin solution for several days, and then embedded in $5 \%$ and $10 \%$ gelatin solution, respectively, for 1 day. Brains of the animals were sectioned in the coronal plane at $25 \mu \mathrm{m}$ and every fifth section was mounted and stained with hematoxylin. 


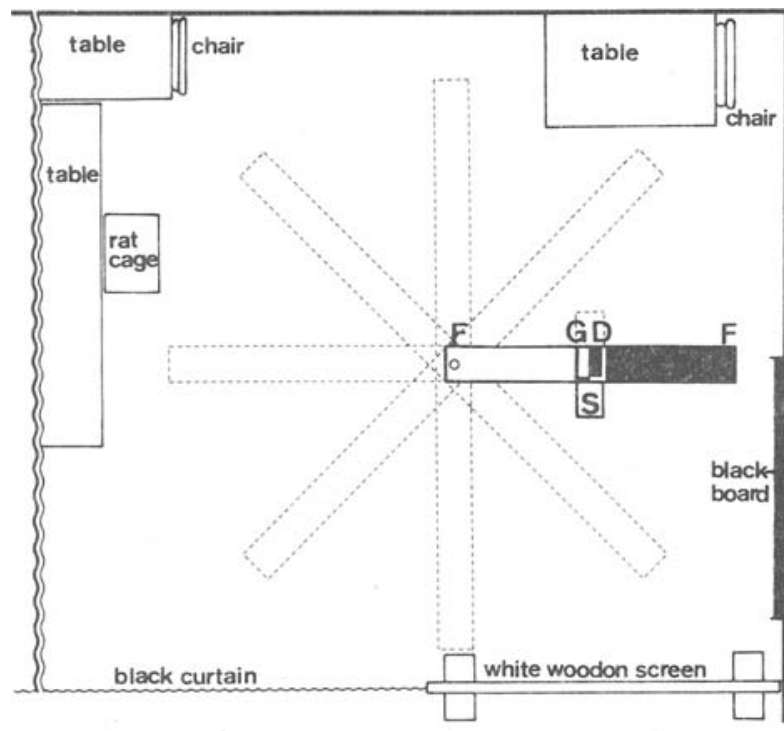

Figure 1. The apparatus and layout of the experimental room. Dotted lines show the possible pasitions for the apparatus. $S=$ starting area, $F=$ food cup, $G D=$ guillotine doors.

\section{Apparatus}

The apparatus and arrangement of the experimental room are shown in Figure 1. An elevated wooden T-maze, which consisted of two arms (each $70 \mathrm{~cm}$ long) and a stem (13.7 cm long), was used. At the ends of each arm, small holes were provided for food pellets. The floor of one arm of the maze was painted white, the other black, and the stem was painted gray; this was the maze with the intramaze cues. For the place task, the floors of both arms were covered by gray painted inserts for the last phase of training (see below). Two transparent guillotine doors were placed at the entrance of each arm, and a third door was located at the exit of the stem. The apparatus could be rotated to eight different positions in the room, with the end of one arm remaining at a fixed point (see Figure 1).

\section{Procedure}

One week following surgery, food was removed from the cages and body weights of the animals were reduced over several days to approximately $80 \%$ of their free-feeding weights. This level was maintained throughout testing by feeding the appropriate amount of food after each day's trials. For the first 2 days of the feeding schedule, the rats were handled for approximately 5 min each day. On the following day they were placed in the T-maze for $10 \mathrm{~min}$ for habituation. During training on both the place and the cue task, each subject was given 16 trials each day for 8 days. The intertrial interval was either 40,60 , or $80 \mathrm{sec}$ (averaging $60 \mathrm{sec}$ ). Twentythree rats (14 hippocampals, 5 operated controls, 4 unoperated controls) were trained first on the cue task, and this was followed by training on the place task (C-P order). The remaining 17 rats ( 9 hippocampals, 5 operated controls, and 3 unoperated controls) were trained in the reverse order; that is, they were trained first on the place task and then the cue task (P-C order). After completion of training on the first task (either place or cue), the animals received 2 weeks of ad-lib feeding, after which the food was removed again and the animals were placed on the feeding regimen that had existed during the first training phase. During the 1 day of habituation, each rat was allowed to run about the maze and eat $45-\mathrm{mg}$ food pellets that had been placed at the end of each arm. This procedure was repeated 16 times. Following the day of habituation, training on the second task was begun.
In the cue task, each rat was trained to run to the end of the white arm for food reward. After the subject was put into the stem, the experimenter lifted the doors, and the rat was allowed to run into either arm. Rats were trained with a noncorrection procedure. When the animal reached the end of the arm, the doors were closed and the trial ended. If the rat had not reached the end of either arm within 2 min, the doors were closed and the trial ended. The black and white arms of the maze were placed equally often at the center site of the eight radial positions. In addition, the stem, which was the starting area, was placed on different sides of the maze on different trials. Thus, there were 32 possible combinations ( 8 maze positions $\times 2$ arm stimuli $\times 2$ stem positions). Subjects experienced all of the 32 different possible combinations in random order over 2 days, for a total of 8 days, 16 trials each day.

In the place task, each rat was trained to run to the end of the arm that was located at the central site of the radial position. The white and the black arm were placed at the central site on different trials, and the stem was moved to either side of the maze, resulting in four possible combinations ( 2 arm stimuli $\times 2$ stem positions). These combinations were repeated four times in random order on each training day.

For the subjects that were trained first on the cue task and then on the place task, 4 additional days of training on the place task were carried out. The testing was similar to that previously employed, except that the black and white intramaze stimuli were replaced with the gray inserts. As before, the stem was moved to either side of the maze in random order. A 10-day period with no testing was inserted between the first 2 days of additional training and the second 2 days.

\section{Measures of Performance and Data Analysis}

The data were converted to the percentage of correct responses in each block of trials by dividing the total number of trials (16) into the number of correct responses for that day. Running time was defined as the time from the raising of the doors to the time when the rats reached the end of an arm. These data were transformed into logarithms.

In this experiment there were three strategies the rats could use in carrying out the tasks: the cue strategy (choosing the black or white arm), the place strategy (choosing the center or distal site), and the response strategy (right turn or left turn). The procedure used to specify how often each strategy was utilized when performing the tasks will be described in the Results section. Statistical analysis of the data was carried out using a factorial design analysis of variance (ANOVA) with block-treatment confounding, and tests of simple main effects were used for further analysis of significant effects (Kirk, 1968). These analyses were applied to the data resulting from training on the cue task and the place task for both the $\mathrm{C}-\mathrm{P}$ and the P-C order.

\section{RESULTS}

\section{Histological}

Figure 2 presents microphotographs of coronal sections from a representative hippocampectomized rat. In all of the hippocampals, the dorsal hippocampus and fimbriafornix were completely transected bilaterally, while the ventral hippocampus was spared. In addition to damage to the cingulate cortex and corpus callosum, some nuclei in the dorsal portion of the thalamus (lateral, anteroventral, anterodorsal, and dorsomedial), stria terminalis, stria medullaris, and/or lateral septum were partially damaged in some of the hippocampals. None of the controls received damage to the hippocampus or fimbriafornix. Both the hippocampal and control subjects had 


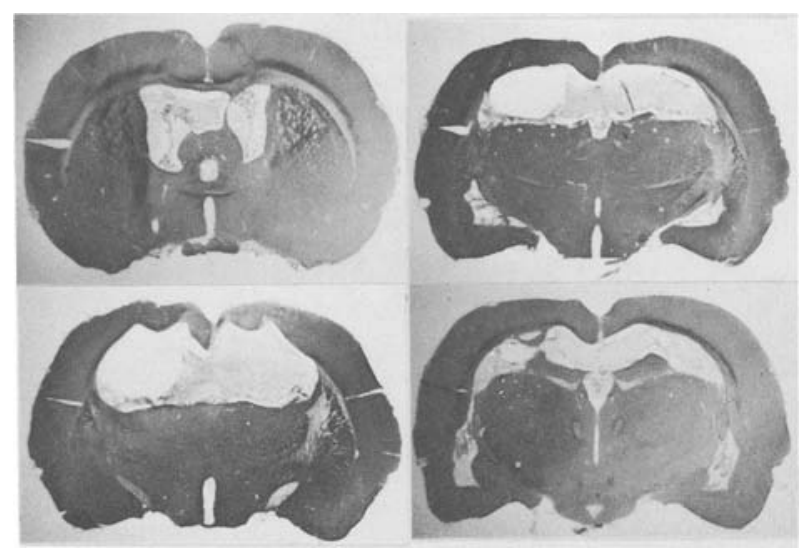

Figure 2. Photomicrographs showing coronal sections from a representative animal in the hippocampal lesion group.

some damage to that part of the neocortex through which the electrode had been inserted.

\section{Behavioral}

Preliminary analyses of all dependent variables indicated equivalent performance by the operated and unoperated control groups. Therefore, the two groups were combined to form a single control group. Since a number of subjects did not reach the end of either arm during the 2-min limit during early training, the behavioral data for Day 1 were not included in the analyses.

The percentages of correct responses for both the controls and hippocampals and for both orders of testing are shown in Figure 3. Both the hippocampals and the controls, which performed at chance levels at first, improved their performance on the cue task to better than $90 \%$ correct by the end of training. The main effect of days was significant for both the C-P and the P-C order $[F(6,114)$ $=17.46$ and $F(7,105)=21.37$, respectively, $p$ s $<.01]$. The performance curves for both groups in the C-P order and for the controls in the P-C order did not differ. However, the curve for the hippocampals in the P-C order was different from that of the other groups, and the interaction of groups $\times$ days was significant in the P-C order only $[F(7,105)=4.15, p<.01]$. Further analysis of the significant interaction indicated that there were signifi- cant differences in correct responses between the hippocampals and the control animals on Days 3, 4, and 5 .

On the place task, both the controls and the hippocampals performed at chance early in training. As training progressed, the controls learned to run to the correct place almost perfectly by the last block of trials; however, the hippocampals did not learn to choose the correct place. Main effects of groups and days, and the interaction of the two, were significant $[F(1,19)=27.83, F(7,133)=$ 18.65 , and $F(7,133)=7.34$, respectively, $p s<.01$, for all in the C-P order; $F(1,15)=31.79, F(6,90)=9.97$, and $F(6,90)=4.66$, respectively, $p s<.01$, for all in the P-C order].

In addition to the results for the place task with the black and white intramaze cues in the arms, the results of the task when the gray inserts were added were analyzed (see Figure 3, curves on the right). The controls ran to the correct arm almost perfectly during these four blocks of trials, but the hippocampals showed no progress in learning. Only the main effect of groups was significant $[F(1,19)=38.97, p<.01]$.

The different strategies used by the groups in performing the tasks were also determined. Specifically, the cue strategy rate (CSR) was calculated as follows: $[|X-8 \mathrm{~F}| / 8] \times 100$ (where $X$ is the number of trials on which a rat entered the white end, 8 is the maximum number of possible trials that take place by chance in a block of 16 trials, and 100 is $100 \%$ ). The place and response strategy rates (PSR and RSR) were calculated in the same way: [ $|Y-8| / 8] \times 100$ for PSR (where $Y$ is the number of trials on which a rat reached the arm placed at the central site of radiating positions), and $[|Z-8| / 8] \times 100$ for RSR (where $Z$ is the number of turns in a particular direction, e.g., the number of right turns). $X, Y$, and $Z$ varied from 0 to 16 . Because there were no intramaze stimuli in the place task at the end of training, when intramaze stimuli were eliminated, and during the first four blocks of training for the C-P order, the CSR was not calculated for these additional blocks of trials. Mean percentages of the three strategies for hippocampals and controls are shown in Figure 4.

Regardless of the order of training, the controls used no dominant strategy on the initial training block for either the place or the cue task, but it is apparent that they started

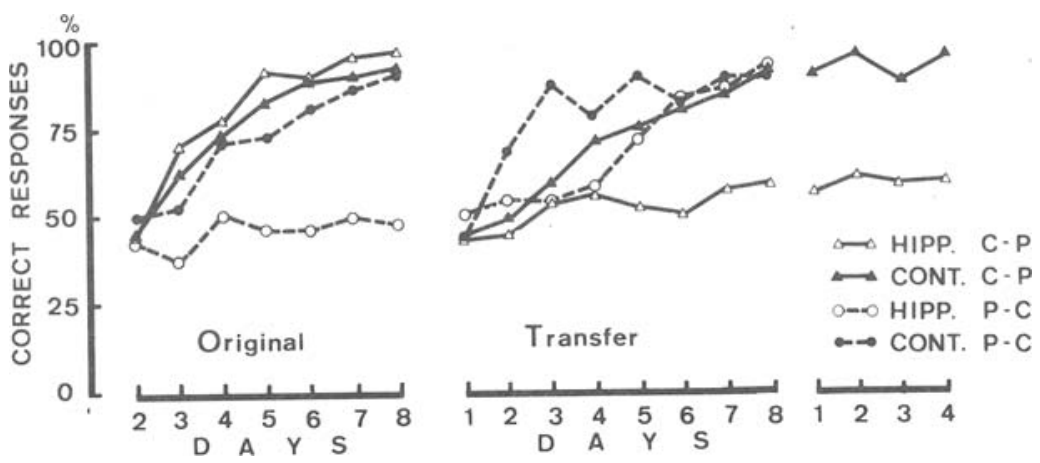

Figure 3. Mean percentages of correct responses for hippocampals and controls on the place and cue tasks. 


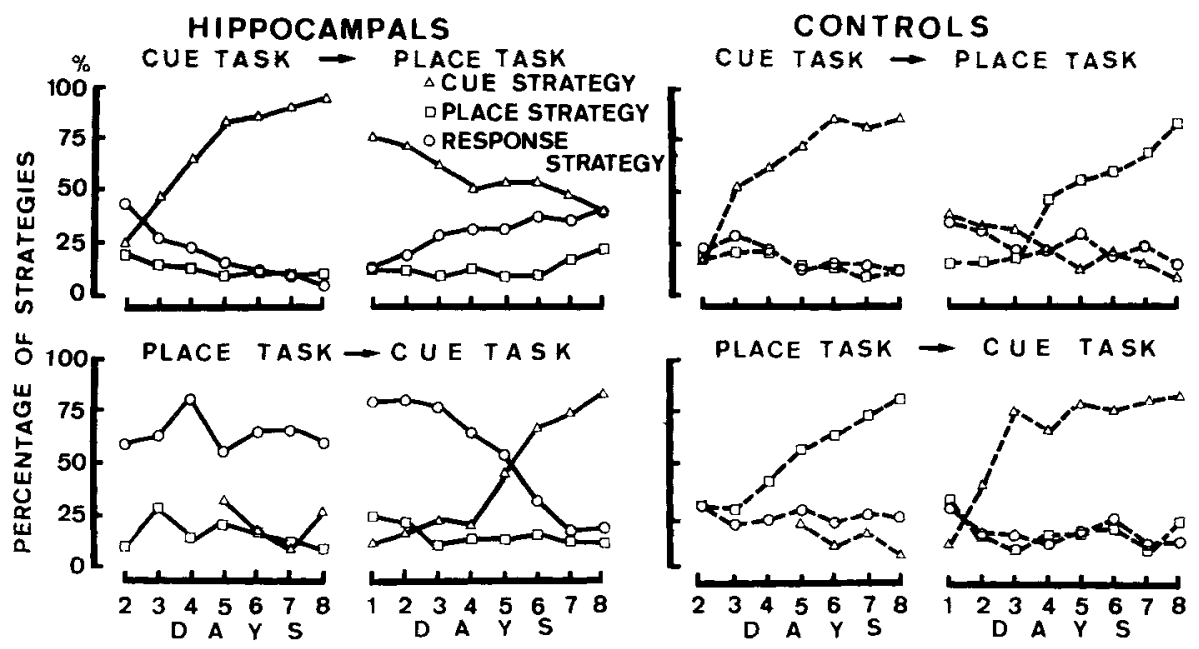

Figure 4. Mean percentages of cue, place, and response strategy for hippocampals and controls on the place and cue tasks.

to use the appropriate strategy for each task as training progressed. The PSR on the place task and the CSR on the cue task increased to more than $80 \%$ by the last block of trials.

On the other hand, the strategy used by the hippocampals was different from the strategy used by the controls at several points. First, the hippocampals failed to use the place strategy on the place task, even though their CSR reached the level of about $80 \%$ on the cue task. In fact, the place strategy was never dominant for hippocampals at any time during training. Second, the hippocampals adopted a response strategy (high level of RSR) when the appropriate place strategy was not utilized on the place task. Third, whatever strategy the hippocampals adopted on the first task, they continued to use it for several days of testing on the subsequent task.

For example, in being tested on the place task after learning the cue task, hippocampals failed to adopt a new strategy and used the acquired cue strategy at a CSR of about $80 \%$. However, they gradually began to use the re- sponse strategy, which was inappropriate for the place task, and the response strategy was dominant on the later blocks. In contrast, the controls started to use the place strategy in the new situation after only a few trials. The results of the ANOVA for the PSR indicated that the main effects of groups and days and the interaction were significant $[F(1,19)=33.63, F(7,133)=8.47$, and $F(7,133)$ $=7.16$, respectively, $p \mathrm{~s}<.01]$; the main effects of groups and days were significant for the CSR $[F(1,19)$ $=9.25$ and $F(7,133)=5.36, p s<.01]$; and the interaction was significant for the $\operatorname{RSR}[F(7,133)=2.74$, $p<.05]$.

In the P-C order, the hippocampals mainly used the response strategy in the place task, and they continued to use it in the beginning blocks of the cue task. However, they started to use the cue strategy as training progressed, and gradually the cue strategy became dominant. The results of the ANOVA of the place task data indicated that the main effect of groups was significant for the PSR $[F(1,15)=26.90, p<.01]$ and the RSR $[F(1,15)=$
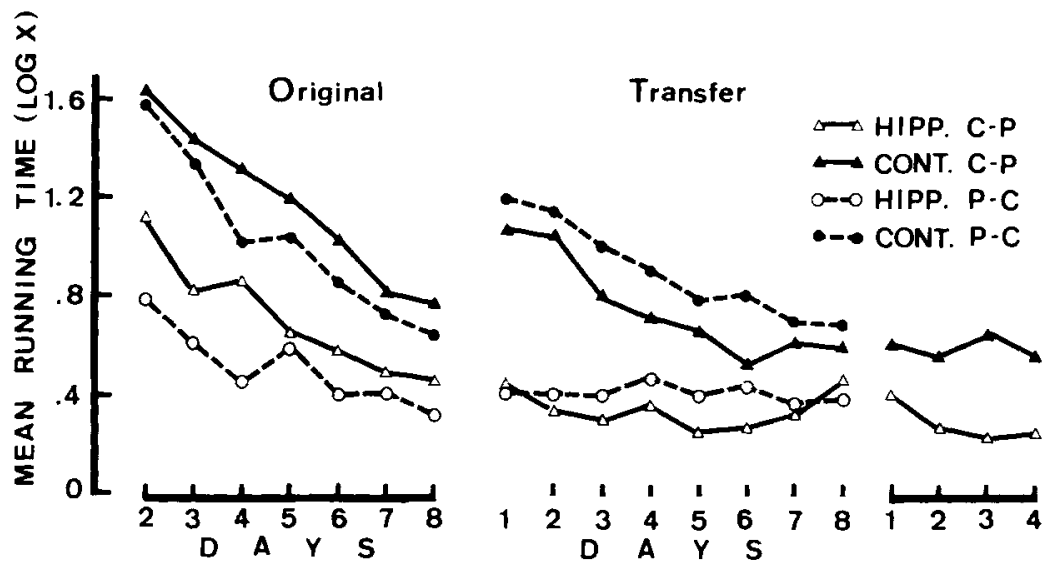

Figure 5. Mean running times for the hippocampal and control animals on the place and cue tasks. 
$16.58, p<.011$, but not for the CSR. In the cue task, the interaction of groups and days was significant for the $\operatorname{RSR}[F(7,105)=6.26, p<.01]$ and the CSR $[F(7,105)$ $=3.88, p<.01]$.

Figure 5 shows the mean running times for each group in the C-P and P-C orders. Running times of both controls and hippocampals gradually decreased with training. However, when the controls were changed to the new training conditions, their running times temporarily lengthened. In contrast, the running times of hippocampals continued to decrease even when the task was changed. As shown in Figure 5, running times for both controls and hippocampals in the P-C order were similar to those in the $\mathrm{C}-\mathrm{P}$ order during the first phase of testing. Therefore, only the results of the ANOVA for the P-C order are presented. The main effects of groups and days and the interaction were significant at the $p<.01$ level $[F(1,15)=12.47$, $F(6,90)=39.31$, and $F(6,90)=5.98$, respectively, for the place task; $F(1,15)=12.70, F(7,105)=6.41$, and $F(7,105)=6.24$, respectively, for the cue task].

\section{DISCUSSION}

The results of the present experiment confirmed the expectation, derived from the cognitive map theory, that performance of the hippocampals would be impaired, compared with that of the controls, on the place task ( $O^{\prime}$ Keefe \& Nadel, 1978). Because lesions of the hippocampus destroy the cognitive map, it was expected that rats with these lesions could not solve the place task. Because the same lesions do not destroy the ability to learn the cue task, it was expected that hippocampals could perform the cue task with little difficulty. These were the obtained results. According to the theory, under some conditions, hippocampals should be able to perform a cue task somewhat better than controls. O'Keefe, Nadel, Keightly, and Kill (1975) stated that "removal of the possibility of a competing place hypothesis should hasten the choice of a cue hypothesis" (p. 159) for the hippocampals in the cue task. Although correct response rates of the hippocampals were clearly better than those of the controls in the C-P order of testing (see Figure 3), the differences were not statistically significant. The finding of normal performance of hippocampals on a cue task agrees with the results recently reported by other investigators (Aggleton, Hunt, \& Rawlins, 1986; Jarrard, 1986; Jarrard et al., 1984; Morris et al., 1982; Nadel \& MacDonald, 1980).

Of special interest were the results of the analysis of the strategies that were employed by the various groups. The controls used the appropriate strategy for both the place task and the cue task. In contrast, the hippocampals used the cue strategy in the cue task, but were not able to use the place strategy in the place task. In this regard, the results derived from analysis of the strategies that were employed supported the predictions of the cognitive map hypothesis. The hippocampals did not use the place strategy in performing the place task, but rather used primarily the response strategy. In hippocampals that were tested on the place task during the first phase of training, the response strategy was adopted from the beginning of training. Hippocampals that learned the place task as the second training task gradually replaced the cue strategy, which had been acquired in the first task, with a new response strategy (i.e., right or left turn). Even though hippocampals did not use the cue strategy from the beginning of training in the cue task, they did use the cue strategy by the end of training. These results suggest that lesions of the hippocampus destroy the ability to utilize the place strategy, but not the ability to utilize other strategies.

According to Olton et al.'s (1979) working memory hypothesis, rats with hippocampal lesions should show impairment on a task that requires working memory, but no impairment on a task that requires only reference memory. In order to correctly perform the place task in the present experiment, it was necessary for the rat to retain the relevant information over trials; thus, the task was a reference memory task. If the hippocampus involves only working memory, as Olton et al. asserted, the hippocampals in our experiment should have performed the place task as well as the control rats. The results of the present experiment, however, show that the hippocampals' performance on the place task was significantly poorer than that of the controls. Thus, this experiment does not support Olton et al.'s working memory hypothesis.

In the cue-utilization hypothesis advanced by Winocur $(1980,1982)$, the general information-processing deficit that is found following damage to the hippocampus is lessened when the salience of relevant task-related cues is increased. Thus, the intramaze cues in the present cue task enhanced the discriminability between competing associations, and the hippocampals were not impaired. Winocur's hypothesis would posit that the hippocampals' impaired performance on the present place task was due, in part, to a lack of saliency of cues. However, the present results and those reported by Oshima and Okaichi (1985) argue against this position. In the latter experiment, a T-maze similar to that used in the present study was employed, but it was placed in the center of the experimental room. As a result, extramaze cues were less distinct than those in the present experiment, because both ends of each arm were equidistant from the closest wall. Controls found sufficient cues to utilize on the place tasks in both the offcentered T-maze of the present experiment and the centered T-maze used by Oshima and Okaichi, and in both cases exhibited excellent learning. If Winocur's hypothesis were correct, hippocampals should exhibit some learning, using the more salient and distinct cues available in the off-centered maze; in the centered T-maze, however, they should not be capable of utilizing the less salient cues and should exhibit impaired learning. In fact, the results show that hippocampals were unable to learn in either situation. The greater saliency of cues available for utilization in the off-centered T-maze used in the present study 
did not help the hippocampals learn the place task. As predicted by O'Keefe and Nadel (1978), hippocampals were unable to learn in either situation requiring the use of a cognitive map.

Analysis of the strategies used by the rats in the present experiment shows that hippocampals utilized the relevant cue strategy on the cue task, but an irrelevant response strategy on the place task (Figure 4). This might be explained by Moore's (1979) "tuning-out" hypothesis. According to this view, hippocampals are impaired on tasks that require the tuning out of redundant and/or irrelevant stimuli. At an early stage of training on the place task, a rat may associate reward with compound stimuli: proprioceptive cues resulting from turning (and running) behavior to the correct arm, and extramaze cues that surround the correct arm. When a rat chooses the correct arm, proprioceptive cues caused by turning left or right are associated with the reward at the rate of $50 \%$, whereas extramaze cues are always associated with the reward. Therefore, controls learn to tune out proprioceptive cues and strengthen the association between reward and extramaze cues. On the contrary, hippocampals do not tune out proprioceptive cues (the response strategy). According to Moore, the cue task would not be as difficult as the place task; thus, there would be less interference from irrelevant events and less need to ignore or tune out irrelevant stimuli.

The strategies that were acquired in the first task were transferred to the second task to a greater extent in hippocampals than in controls. This perseverative behavior could be interpreted as partially supporting the earlier inhibition hypothesis advanced by Kimble and Kimble (1970). According to this view, hippocampals continue to use the previously acquired strategy, and it is difficult for them to adopt a new one. A second way of interpreting the finding was provided by one of the reviewers of this paper. It was suggested that the different levels of reinforcement received by the two groups on the first task could explain the relatively fast shifting on the part of controls. Thus, on the place task, hippocampals were being reinforced on $50 \%$ of the trials, whereas controls were receiving $100 \%$ reinforcement. When transferred to the cue task, hippocampals could maintain the same rate of reinforcement by maintaining their original strategy, whereas controls would receive only half the previous level of reinforcement. Thus, the reward rate contrast could well facilitate shifting strategies in controls but not in hippocampals. Other research will be needed to see which explanation is correct.

In summary, rats with hippocampal lesions were unable to learn the simple place task used in the present experiment. In contrast, hippocampals learned the cue task with fewer errors than controls, although the difference was not statistically significant. The rats with hippocampal lesions used the appropriate cue strategy on the cue task, but never learned to use a place strategy. On the place task, instead of using a place strategy, the lesioned rats fixated by going either to the right or to the left; that is, they used a response strategy. Generally, the results of the present research can best be interpreted as supporting O'Keefe and Nadel's (1978) cognitive map theory.

\section{REFERENCES}

Aggleton, J. P., Hunt, P. R., Rawlins, J. N. P. (1986). The effects of hippocampal lesions upon spatial and non-spatial tests of working memory. Behavioral Brain Research, 19, 133-146.

JARRARD, L. E. (1986). Selective hippocampal lesions and behavior: Implications for current research and theorizing. In R. L. Isaacson \& K. Pribram (Eds.), The hippocampus (pp. 93-126). New York: Plenum Press.

Jarrard, L. E., Okaichi, H., Strward, O., \& Goldschmidt, R. (1984). On the role of the hippocampal connections in the performance of place and cue tasks: Comparisons with damage to hippocampus. Behavioral Neuroscience, 98, 946-954.

Kimble, D. P., \& Kimble, R. J. (1970). The effect of hippocampal lesions on extinction and "hypothesis" behavior in rats. Physiology \& Behavior, 5, 735-738.

KIRK, R. E. (1968). Experimental design: Procedures for the behavioral sciences. Belmont, CA: Brooks/Cole.

MOORE, J. W. (1979). Information processing in space-time by the hippocampus. Physiological Psychology, 7, 224-232.

Morris, R. G. M., Garrud, P., Rawlins, J. N. P., \& O'Keefe, J. (1982). Place navigation impaired in rats with hippocampal lesions. Nature, 297, 681-683.

NADEL, L., \& MACDonald, L. (1980). Hippocampus: Cognitive map or working memory? Behavioral \& Neural Biology, 29, 405-409.

OKeEFE, J., NADEL, L. (1978). The hippocampus as a cognitive map. Oxford: Clarendon Press.

O'Keefe, J., Nadel, L., Keightly, S., \& Kill, D. (1975). Fornix lesions selectively abolish place learning in the rat. Experimental Neurology, 48, 152-166.

Olton, D. S., Becker, J. T., Handelmann, G. E. (1979). Hippocampus, space, and memory. Behavioral \& Brain Sciences, 2, 313. 365. (Includes commentary)

OltoN, D. S., \& FeustLE, W. A. (1981). Hippocampal function required for nonspatial working memory. Experimental Brain Research, 41, 380-389.

Oshima, Y., \& OKaICHI, H. (1985). Learning strategies of hippocampectomized rats on an elevated maze. Japanese Journal of Psychology, 56, 241-244. (in Japanese)

WALKER, J. A., \& Olton, D. S. (1984). Fimbria-fornix lesions impair spatial working memory but not cognitive mapping. Behavioral Neuroscience, $98,226-242$

Winocur, G. (1980). The hippocampus and cue utilization. Physiological Psychology, 8, 280-288.

WINOCUR, G. (1982). Radial-arm-maze behavior by rats with dorsal hippocampal lesions: Effect of cuing. Joumal of Comparative \& Physiological Psychology, 96, 155-169.

(Manuscript received September 11, 1986; revision accepted for publication January 16, 1987.) 